\title{
Flutter Derivatives Identification and Aerodynamic Performance of an Optimized Multibox Bridge Deck
}

\author{
Zhida Wang and Elena Dragomirescu \\ The University of Ottawa, 161 Louis Pasteur, Ottawa, ON, Canada K1N 6N5 \\ Correspondence should be addressed to Elena Dragomirescu; elndrag@uottawa.ca
}

Received 12 March 2016; Accepted 26 July 2016

Academic Editor: Ghassan Chehab

Copyright (c) 2016 Z. Wang and E. Dragomirescu. This is an open access article distributed under the Creative Commons Attribution License, which permits unrestricted use, distribution, and reproduction in any medium, provided the original work is properly cited.

\begin{abstract}
The bridge deck sections used for long-span suspension bridges have evolved through the years, from the compact box deck girders geometrical configurations to twin-box and three-box bridge decks sections. The latest generation of split and multiplebox bridge decks proved to have better aerodynamic behavior; thus further optimization methods are sought for such geometrical configurations. A new type of multibox bridge deck, consisting of four aerodynamically shaped deck boxes, two side decks for the traffic lanes and two middle decks for the railway traffic, connected between them by stabilizing beams, was tested in the wind tunnel for identifying the flutter derivatives and to verify the aerodynamic performance of the proposed multibox deck. Aerodynamic static force coefficients were measured for the multibox bridge deck model, scaled 1:80, for Reynolds numbers up to $5.1 \times 10^{5}$, under angles of attack between $-8^{\circ}$ and $8^{\circ}$. Iterative Least Squares (ILS) method was employed for identifying the flutter derivatives of the multibox bridge deck model, based on the results obtained from the free vibration tests and based on the frequency analysis the critical flutter wind speed for the corresponding prototype of the multibox bridge was estimated at $188 \mathrm{~m} / \mathrm{s}$.
\end{abstract}

\section{Introduction}

After the failure of the of the first Tacoma Narrow Bridge at half of its design wind speed, bridge which was designed to withstand static wind load only, various methods have been adopted for analyzing the aerodynamic instability of long-span bridges, with the assistance of wind tunnel tests ([1-3], etc.). Nowadays, the aerodynamic stability criteria for suspension and cable-stayed bridges have been wellestablished ([4-6], etc.) and new challenges were raised in terms of the bridge deck geometrical configurations leading to the new generation of slotted bridge deck geometries ([7-9], etc.) with improved the aerodynamic performance, which allowed the development of longer bridge spans ([10, 11]). These new concepts of "synthetic" flutter control were discussed by Miyata [12] in an attempt to lower the flutter onset wind speed, which the Japanese design standards requirements set to $80 \mathrm{~m} / \mathrm{s}$, by proposing modifications of the deck cross section. The "spindle-type" bridge deck he proposed had the deck divided into two symmetric box decks on the main span only, while on the lateral spans a conventional closed box deck was used; however the critical flutter modes proved to be asymmetric for the main span and symmetric for the side spans. Several twin-box deck bridges have been constructed recently, such as Stonecutters Bridge of $1,377 \mathrm{~m}$ main span [13], Tsing Ma Bridge with main span of $1,650 \mathrm{~m}$ [14], and Xihoumen Bridge of 1,410 m main span [11], and three-box bridge decks have also been designed for Messina Bridge [7, 15], Gibraltar Strait Bridge [16], and Sunda Strait Bridge [17]; however none of these bridges were constructed yet. In order to investigate the impact of different deck cross-sectional configurations for bridges with torsional to vertical frequencies ratio lower than unity, on the aerodynamic stability, but also on the cost reductions, implied by the construction solution, Bartoli et al. [18] analyzed several deck cross sections using the same width and then increased width with regard to the reference Messina Bridge, but eliminating the middle deck. Also most of the mass of 


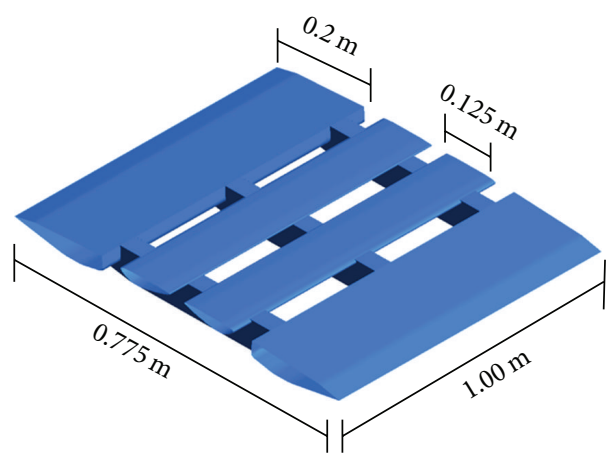

(a)

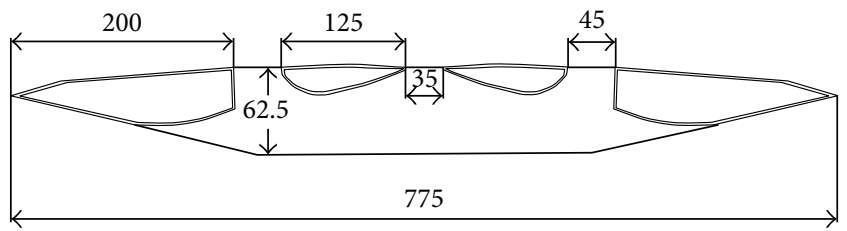

(b)

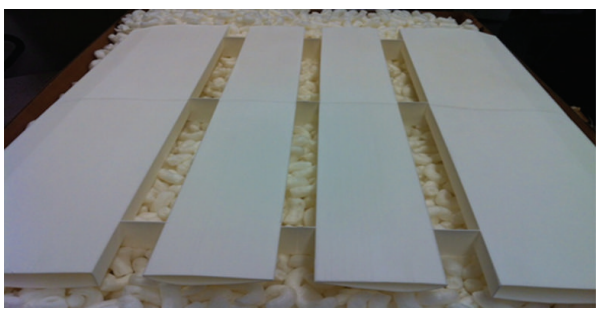

(c)

Figure 1: Dimensions of the four deck bridge deck model: (a) general layout (mm), (b) model cross section, and (c) 3D printed ABS hollow shell decks.

the deck models was situated outside the main cables and hangers plane. The innovative design strategy proposed was to achieve deck models with torsional to vertical frequency ratio lower than unity such that the classical flutter instability is avoided, and thus complex aerodynamic optimizations of the bridge deck would not be required. According to the study made by Ge and Xiang [11] a very long main span of 5,000 m can be achieved for a suspension bridge either by employing a wide slotted deck or a narrow slotted deck with vertical with horizontal stabilizers, for which the critical flutter speed of $86 \mathrm{~m} / \mathrm{s}$ or higher was estimated as sufficient to withstand the wind loads in the most of the typhoon prone areas worldwide.

Thus, in order to further improve the aerodynamic characteristics of long-span suspension bridges, an optimized multibox bridge deck model with two side decks for traffic lanes, two middle railway decks, and a total of 3 gaps separating them, is proposed and experimental verification of its aerodynamic performance was performed. Wind tunnel tests were carried out on the 1:80 scaled four-boxes deck model, for angles of attack of $-8^{\circ},-6^{\circ},-4^{\circ},-2^{\circ}, 0^{\circ}, 2^{\circ}, 4^{\circ}$, $6^{\circ}$, and $8^{\circ}$ and $\operatorname{Re}$ numbers up to $5.1 \times 10^{5}$. The static lift and drag force coefficients $C_{L}$ and $C_{D}$ corresponding to the measured lift and drag aerodynamic forces were determined from the experiment at different wind speeds. Also the extraction of the flutter derivatives was performed using the Iterative Least Square (ILS) method proposed by Chowdhury and Sarkar [19]. The flutter performance of the proposed multideck bridge section was discussed with regard to the thin plate flutter theory and was also compared with the flutter derivatives reported in the literature for other bridges with one, two, and three decks configurations.

\section{Experimental Setup for the Multibox Bridge Deck Model}

The new multideck bridge deck model has a total of four airfoil shaped decks with three gaps separating them; its streamlined geometry, along with the three slots between the decks, is expected to confer improved aerodynamic characteristics and higher flutter wind speed for the bridge deck model. The length of the sectional model was $1.00 \mathrm{~m}$ and the total width was $0.775 \mathrm{~m}$, while the two middle decks used for railway had $0.125 \mathrm{~m}$ width each and the gap between them was $0.035 \mathrm{~m}$, as represented in Figure 1(a). The traffic side decks had a width of $0.2 \mathrm{~m}$ and the gaps separating them from the middle decks were $0.045 \mathrm{~m}$ each. The four airfoil decks of the section model were connected by three beams with a depth of $0.0625 \mathrm{~m}$ each (Figure 1(b)). The streamlined airfoil shape of the individual decks was very difficult to construct using plywood, which is the most common material used for wind tunnel models; therefore a shell model was first created out of Acrylonitrile Butadiene Styrene (ABS) plastic material, through the $3 \mathrm{D}$ printing technique, to ensure an exact replication of the prototype curved cross section of the decks and of the cross-beams (Figure 1(c)). Due to the dimensions of the section model, the shell was printed in four parts, which were connected together. Four low density foam cores with the same geometry of the deck shells, precisely shaped using hot-wire cutting technique, were inserted inside each deck shell and inside the cross-beams connecting the four decks, to maintain the homogeneity of the deck model. As the ABS plastic is much more flexible than the wood material used for bridge deck models, four aircraft-graded aluminum strips with $0.4 \mathrm{~cm}$ thickness were attached on 


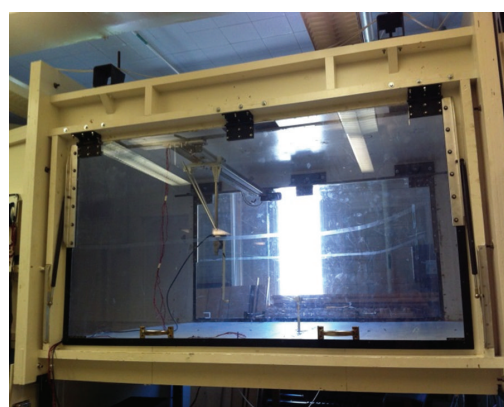

(a)

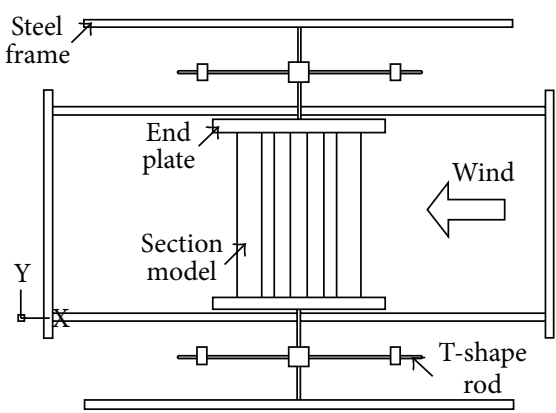

(b)

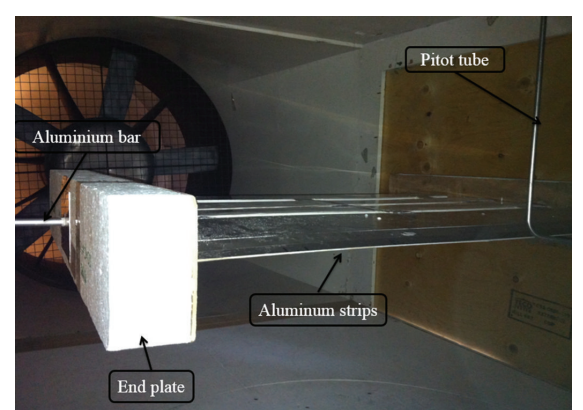

(c)

FIGURE 2: (a) Wind tunnel test section, (b) springs suspension system, and (c) experimental setting of the multibox bridge deck model.

the top surface of the decks, to increase the resistance to bending and to eliminate the surface roughness along the deck model. Such test model improving technique is commonly used in wind tunnel testing.

Experiments were carried out in an open circuit, suction wind tunnel which had two test sections of $1.12 \mathrm{~m}$ height, $1.68 \mathrm{~m}$ width, and $2.44 \mathrm{~m}$ length. Each test section allows access to the model from both lateral sides, where horizontally hinged Plexiglas windows are installed, and from the wind tunnel floor (Figure 2(a)). The multibox bridge deck section model was mounted on a spring suspension system consisting of a total of 8 springs, 4 springs on each side of the model (Figure 2(b)), with an equivalent elastic constant for the entire model of $k_{\mathrm{eq}}=680 \mathrm{~N} / \mathrm{m}$. Wind tunnel tests were carried out in smooth flow conditions, on the $1: 80$ scaled multibox bridge deck model, for angles of attack of $-8^{\circ},-6^{\circ},-4^{\circ},-2^{\circ}, 0^{\circ}, 2^{\circ}, 4^{\circ}, 6^{\circ}$, and $8^{\circ}$, for Re numbers up to $5.1 \times 10^{5}$.

The test wind speeds started from $3.0 \mathrm{~m} / \mathrm{s}$ and ranged until the maximum testing wind speed of $13.0 \mathrm{~m} / \mathrm{s}$; higher wind speeds of up to $17.0 \mathrm{~m} / \mathrm{s}$ can be achieved in the wind tunnel; however the experiment was stopped whenever the vertical and torsional vibrations were noticed to become too aggressive, in order to avoid any permanent damage of the bridge deck model or of the mounting system.

Two foam rectangular shape end plates were installed at the extremities of the bridge section model (Figure 2(c)), in order to reduce the end-effect (turbulent flow formed because of the sudden termination of the model) and to ensure two-dimensional flows evolution over the model during the tests. Two aluminum bars reached out from the endplates of the multibox bridge deck model and were connected to two force balance devices, to measure the wind-induced force on the horizontal $x$ - and vertical $z$-axes, respectively. Also the aluminum bar connected the model to the spring suspension system installed outside the wind tunnel, and two laser sensors were mounted above the T-bar, which was held in place by the spring suspension system, so that the distance between the fixed top point of the frame and the moving bridge deck model could be recorded. The total weight of the suspended bridge deck model, including the four individual decks, the connecting beams, the end plates, and the connecting aluminum bars, was $5.0 \mathrm{~kg} / \mathrm{m}$ and the vertical and torsional natural frequencies of the model measured in "no wind" conditions were $f_{h}=1.70 \mathrm{~Hz}$ and $f_{\alpha}=2.4 \mathrm{~Hz}$, respectively. Thus the ratio between the torsional and vertical frequencies was $\varepsilon=f_{\alpha} / f_{h}=1.4$, while the damping ratio in the vertical direction was $\xi_{h}=0.0213$, and the damping ratio in the torsional direction was $\xi_{\alpha}=0.0232$. The Scruton number for the multibox bridge deck model tested was $\mathrm{Sc}=$ $2 \pi m \xi_{h} / \rho B^{2}=0.488$, where $m$ is the mass of the model, $\xi_{h}$ is the nondimensional damping, $\rho$ is the air density, and $B$ is the chord of the model. The mass moment of inertia of the model was $I_{m}=0.988 \mathrm{~kg} \cdot \mathrm{m}^{2} / \mathrm{m}$. The natural frequencies of the full-scale multibox deck bridge are not finalized, because the bridge is not yet scheduled to be constructed; however, bridges with similar deck configurations such as Messina Crossing Bridge were designed for construction and extensive studies reported the structural parameters and aerodynamic properties. Thus Sc numbers reported for section deck models of Messina Bridge were between 0.15 and 0.39 , for damping ratios of $2 \times 10^{-3}$ to $5 \times 10^{-3}$ [20]. For 1:60 scaled model of the Messina Bridge deck, Diana et al. [21] investigated the response of the model for several frequencies of $0.2 \mathrm{~Hz}, 0.5 \mathrm{~Hz}, 0.9 \mathrm{~Hz}, 2 \mathrm{~Hz}, 3.0 \mathrm{~Hz}$, and $4.0 \mathrm{~Hz}$, for wind velocities of $4 \mathrm{~m} / \mathrm{s}, 6 \mathrm{~m} / \mathrm{s}, 10 \mathrm{~m} / \mathrm{s}$, and $14 \mathrm{~m} / \mathrm{s}$. The structural parameters of the currently tested multibox bridge model are within the values reported for Messina Bridge deck. The eigenfrequencies obtained for the first 25 modes from an aeroelastic model of the Messina Bridge showed that the modal parameters were in the range of $0.52 \mathrm{~Hz}$ to $2.30 \mathrm{~Hz}$ [7], with a structural damping of the order of $1 \%$ of the critical damping, for the fundamental modes. Therefore, for the experiments performed by Diana et al. [7] and Diana et al. [20] the first bending mode of vibration ratio between the sectional model and the real Messina Bridge is around $f_{m}=f_{p}=3.8$, and the velocity similarity was around $(U / B f)_{m}=(U / B f)_{p}=2.4$, where the index $m$ stands for the model and the index $p$ stands for the prototype. Considering the similarity between the modal parameters and the test wind speeds used for the current multibox bridge deck model, similar frequency and velocity scale values can be considered when preparing the multibox bridge for design and construction. 


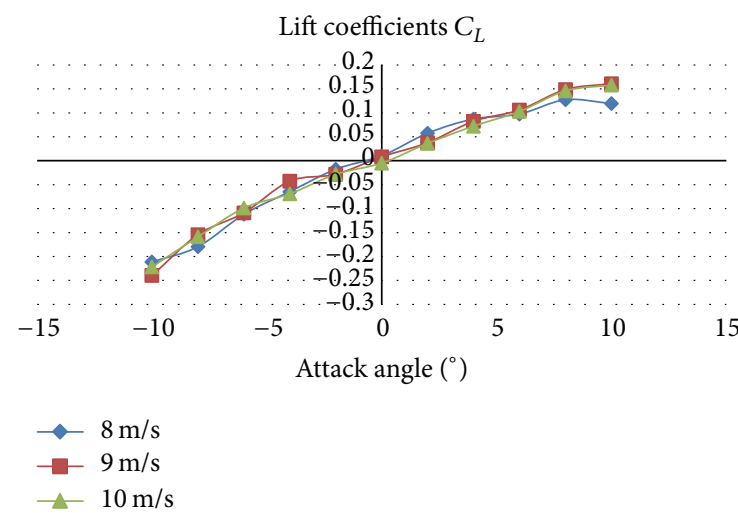

(a)
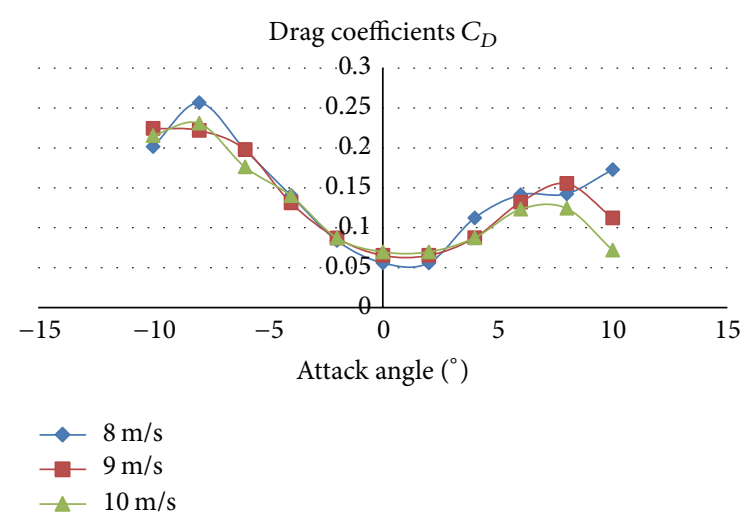

$-10 \mathrm{~m} / \mathrm{s}$

Figure 3: Aerodynamic force coefficients: (a) lift coefficient $C_{L}$ and (b) drag coefficient $C_{D}$.

\section{Aerodynamic Response of the Multibox Bridge Deck Model}

3.1. Aerodynamic Force Coefficients. The drag and lift force coefficients, which are influenced mainly by the shape of the bridge deck model, as well as the angle of attack, were obtained for $-10^{\circ}$ to $10^{\circ}$ through the two-dimensional tests. The lift and drag forces were measured by the aid of the force balances and the recorded values were used to calculate the static drag and lift coefficients respectively, as recommended by the qusisteady formulation [1]:

$$
\begin{aligned}
& D(\alpha)=\frac{1}{2} \rho U^{2} B C_{D}(\alpha), \\
& L(\alpha)=\frac{1}{2} \rho U^{2} B C_{L}(\alpha),
\end{aligned}
$$

where $C_{D}(\alpha)$ and $C_{L}(\alpha)$ are the nondimensional mean drag and lift force coefficients, $D(\alpha)$ is the drag force, $L(\alpha)$ is the lift force, $B$ is the width of the deck model, $U$ is the mean wind speed, and $\rho$ is the air density. These static force coefficients were measured from $5 \mathrm{~m} / \mathrm{s}$, but it was noticed that these coefficients will gradually become stable and thus independent of Re for higher wind speeds. In order to check if the coefficients are no longer influenced by the Re number and of the wind speed, respectively, the results obtained for $8 \mathrm{~m} / \mathrm{s}, 9 \mathrm{~m} / \mathrm{s}$, and $10 \mathrm{~m} / \mathrm{s}$ were compared in Figures 3(a) and 3 (b). It was noticed that the lift coefficients started at very similar values of $C_{L}=-0.212, C_{L}=-0.239$, and $C_{L}=-0.222$ at $-10^{\circ}$, for wind speeds of $8 \mathrm{~m} / \mathrm{s}, 9 \mathrm{~m} / \mathrm{s}$, and $10 \mathrm{~m} / \mathrm{s}$, respectively, and increased gradually up to $C_{L}=0.120, C_{L}=0.161$, and $C_{L}$ $=0.155$ for $10^{\circ}$ angle of attack (Figure 3(a)). Therefore it can be ascertained that no significant change of the aerodynamic force coefficients occurred with the increase of the wind speed. The drag coefficients measured for $8 \mathrm{~m} / \mathrm{s}, 9 \mathrm{~m} / \mathrm{s}$, and $10 \mathrm{~m} / \mathrm{s}$ had a very similar evolution, except for the case of $10^{\circ}$, where they yield values of $C_{D}=0.173, C_{D}=0.121$, and $C_{D}=$ 0.090 for $8 \mathrm{~m} / \mathrm{s}, 9 \mathrm{~m} / \mathrm{s}$, and $10 \mathrm{~m} / \mathrm{s}$, respectively (Figure 3(b)).

3.2. Vertical and Torsional Wind-Induced Vibrations. Vertical and torsional wind-induced vibrations were measured for angles of attack from $-8^{\circ}$ to $8^{\circ}$, for an interval of 60 seconds for each wind speed case tested, with data sampling rate of $10 \mathrm{~Hz}$. The wind-induced responses for angles of attack of $0^{\circ}$ and $-6^{\circ}$ at the highest wind speed tested for each case which were $13.0 \mathrm{~m} / \mathrm{s}$ and $9.0 \mathrm{~m} / \mathrm{s}$, respectively, are represented in detail in Figure 4 . For $0^{\circ}$ angle of attack, the vertical and torsional responses measured for lower wind speeds had relatively small amplitudes, despite some isolated peaks; along with the increase of the wind speed the vibration magnitudes increased reaching amplitudes of up to the average of $17.0 \mathrm{~mm}$ and $4.6^{\circ}$ for the vertical and torsional vibrations, respecively, recorded for the maximum wind speed of $13.0 \mathrm{~m} / \mathrm{s}$ (Figure $4(\mathrm{a})$ ). Unlike the case of lower wind speeds, of up to $12.0 \mathrm{~m} / \mathrm{s}$, where the multibox bridge section model underwent a harmonic motion, with relatively constant amplitude for both vertical and rotational motions, the responses observed at $13.0 \mathrm{~m} / \mathrm{s}$ were more irregular, especially for the torsional vibration, where the oscilation strongly resembles with the beats phenomena encountered usually for galloping aerodynamic instability. Similar trend of increasing the vibration amplitude with the increase of wind speed was noticed for the vertical and torsional vibrations, for $-6^{\circ}$, when amplitudes of $12.31 \mathrm{~mm}$ and $5.9^{\circ}$ at maximum tested wind speed of only $9.0 \mathrm{~m} / \mathrm{s}$; higher wind speeds could not be tested for $-6^{\circ}$ case, due to the very high torsional response, which actually overturned the model and damaged the support system, towards the end of the experiment.

The average vertical and torsional responses were compared for the angles of attack tested for reduced wind speeds $U / B f$ up to 10.13 and it was noticed that in general the amplitudes of vibration increased gardaually for higher reduced wind speeds of up to $U / B f=8.5$, thereafter a sudden increase being registered for most of the cases (Figures 5(a) and $5(\mathrm{~b})$ ). Also it is interesting to notice that for negative angles of attack the vibration amplitudes were slightly higher than those of the positive angles of attack, especially for lower wind speeds. Similar variation is reflected among the torsional vibrations under the attack angles from $-4^{\circ}$ to $4^{\circ}$. The torsional response amplitude had similar evolution for $-2^{\circ}$ and $2^{\circ}$, increasing gradualy with respect to the increasing wind speed. The vibration amplitude for the cases of $-6^{\circ}$ and 


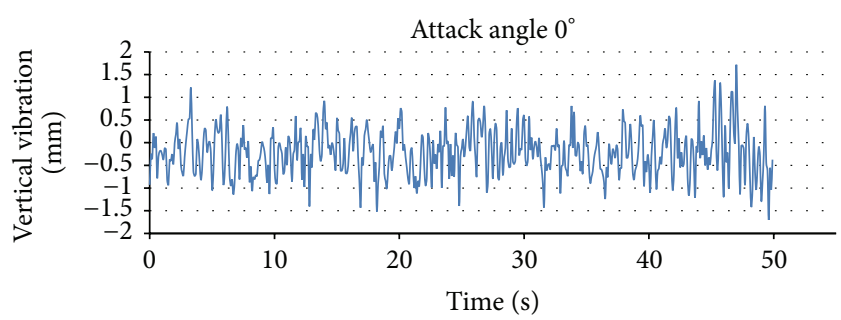

(a)

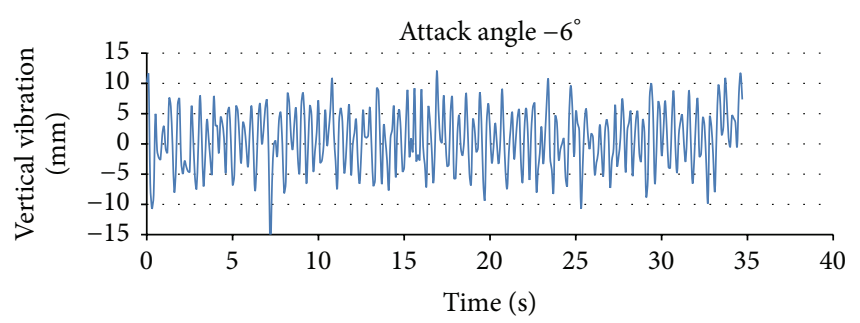

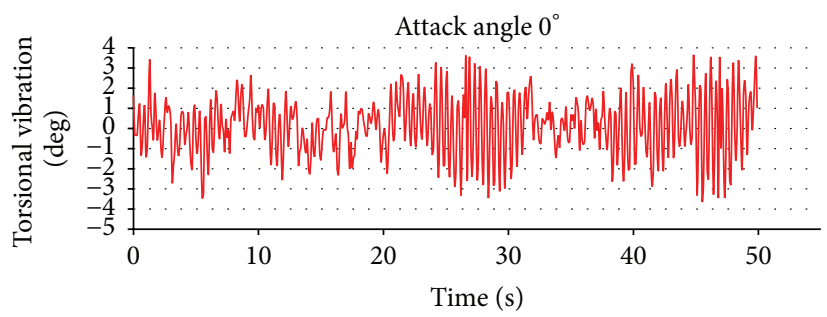

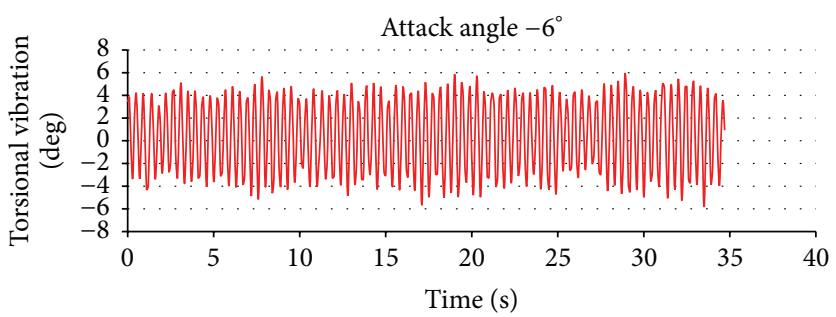

(b)

Figure 4: Vertical and torsional vibrations for (a) $0^{\circ}$ at $13.0 \mathrm{~m} / \mathrm{s}(U / f B=10.13)$ and $(\mathrm{b})-6^{\circ}$ at $9.0 \mathrm{~m} / \mathrm{s}(U / f B=7.01)$.

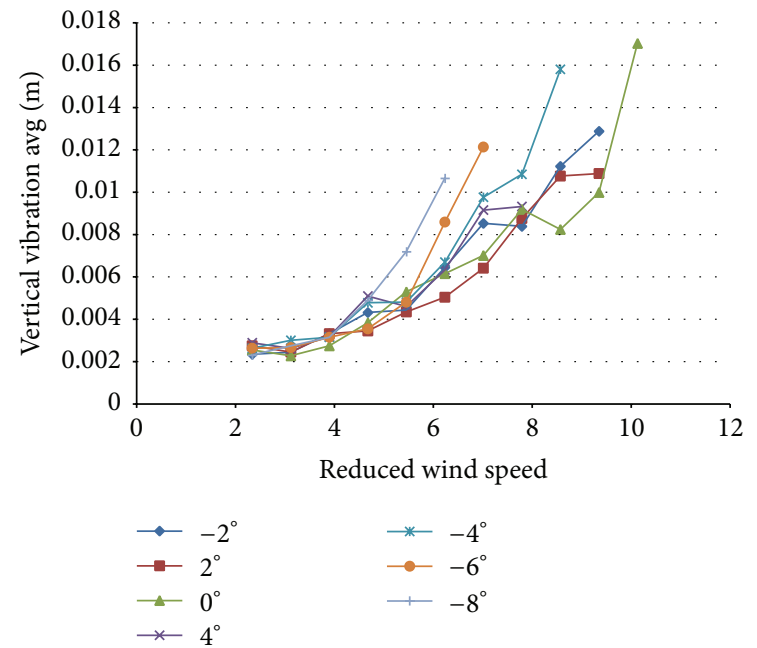

(a)

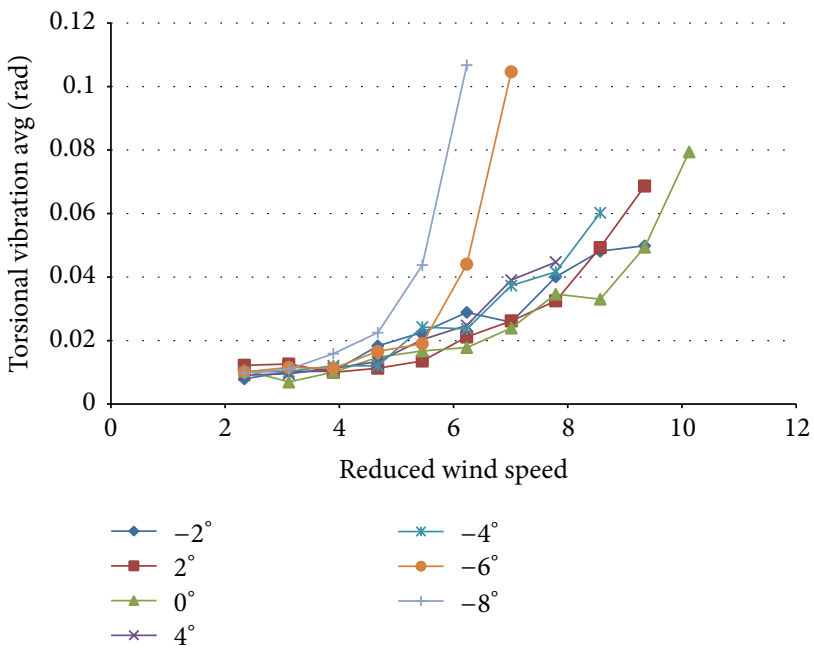

(b)

FIGURE 5: (a) Vertical average response and (b) torsional average response.

$-8^{\circ}$ rapidly increased at a relatively low reduced wind speed of 6.5, especially for the torsional vibrations. Overall, it could be concluded that, for the same amplitude of vibration, the instability of the bridge deck is achieved faster for higher negative angles of attack. Several attempts were perfomed for testing the Megane bridge deck at attack angles of of $6^{\circ}$ and $8^{\circ}$, but because of the previously tested cases, a failiure of the mounting system occurred, and the measured responses were not properly recorded.

\section{Flutter Analysis of the Multibox Bridge Deck Model}

4.1. Flutter Derivatives Identification. The verification for flutter aerodynamic instability is a very important aspect in the design of the long-span suspension bridges. Various experimental and theoretical formulations have been employed for determining the linear expressions for the aerodynamic drag, lift forces and the pitch moment; however, the linearized forms proposed by Simiu and Scanlan [1] are widely accepted by wind engineers worldwide and became the most common expressions for the estimation of the aerodynamic flutter forces per unit length of the bridge deck:

$$
\begin{aligned}
L_{\mathrm{ae}} & =\frac{1}{2} \rho U^{2} B\left(K H_{1}^{*} \frac{\dot{h}}{U}+K H_{2}^{*} \frac{B \dot{\alpha}}{U}+K^{2} H_{3}^{*} \alpha\right. \\
& \left.+K^{2} H_{4}^{*} \frac{h}{B}\right)
\end{aligned}
$$




$$
\begin{aligned}
& M_{\mathrm{ae}}=\frac{1}{2} \rho U^{2} B^{2}\left(K A_{1}^{*} \frac{\dot{h}}{U}+K A_{2}^{*} \frac{B \dot{\alpha}}{U}+K^{2} A_{3}^{*} \alpha\right. \\
& \left.+K^{2} A_{4}^{*} \frac{h}{B}\right),
\end{aligned}
$$

where $B$ is the deck width, $\rho$ is the air density, $U$ is the wind velocity, and the coefficients $H_{i}^{*}$ and $A_{i}^{*}(i=1,2,3,4)$ are known as the Scanlan flutter derivatives. These terms are nondimensional functions of reduced frequency $K$, which is defined as

$$
K=\frac{\omega B}{U}
$$

The adoption of flutter derivatives ensures the quantification of dynamic instability for bridge decks and also provides the unique formulations for aerodynamic forces, regardless of the bridge deck section. The flutter derivatives can be interpreted as the relative changes of the system damping and stiffness with regard to the variation of the wind speed. Unlike the static aerodynamic force coefficients, which can be obtained under static experimental conditions, the flutter derivatives can be measured only if the tested model is in an oscillatory state. However, the identification of flutter derivatives is quite complex and Scanlan and Tomoko [22] introduced the methodology of extracting the flutter derivatives based on the exponentially decaying records of the structural response of the bridge model; one-degree-of-freedom heaving and pitching elastic systems were used to obtain the direct flutter derivatives through wind tunnel testing. With these results, Scanlan and Tomoko [22] conducted two-degree-of-freedom (2-DOF) analysis with coupled frequencies, to extract the rest of the flutter derivatives. The natural frequencies and the damping coefficients obtained for the wind-off test conditions are required when using this approach of extracting the flutter derivatives. However, due to the complexity of the procedure the efficiency and the reliability of this flutter identification method are still debated, as already remarked by Sarkar et al. [23]. In the experiments, the forced method was applied for the multibox bridge deck model which was forced to vibrate in the drag, lift, and moment forces directions, at a constant test wind speed $[20,24]$. Considering the 2-DOF bridge model subjected to aerodynamic forces, the equations of motion along the vertical and rotational directions can be expressed as [1]

$$
\begin{aligned}
& m_{h}\left(\ddot{h}+2 \zeta_{h} \omega_{h} \dot{h}+\omega_{h}^{2} h\right)=L_{h}, \\
& I_{\alpha}\left(\ddot{\alpha}+2 \zeta_{\alpha} \omega_{\alpha} \dot{\alpha}+\omega_{\alpha}^{2} \alpha\right)=M_{\alpha} .
\end{aligned}
$$

By reconstructing $C^{\text {eff }}$ and $K^{\text {eff }}$ matrices, which are the system aeroelastic effective damping and stiffness matrices, respectively, based on the results obtained from each wind speed tested case, the flutter derivatives can be calculated from the difference between these parameters, at the given tested wind speed, and the same parameters obtained for the null wind speed conditions:

$$
\begin{aligned}
& H_{1}^{*}(K)=-\frac{2 m}{\rho B^{2} \omega_{h}}\left(C_{11}^{\mathrm{eff}}-C_{11}^{\mathrm{mech}}\right), \\
& H_{2}^{*}(K)=-\frac{2 m}{\rho B^{3} \omega_{\alpha}}\left(C_{12}^{\mathrm{eff}}-C_{12}^{\mathrm{mech}}\right), \\
& H_{3}^{*}(K)=-\frac{2 m}{\rho B^{3} \omega_{\alpha}^{2}}\left(K_{12}^{\mathrm{eff}}-K_{12}^{\mathrm{mech}}\right), \\
& H_{4}^{*}(K)=-\frac{2 m}{\rho B^{2} \omega_{h}^{2}}\left(K_{11}^{\mathrm{eff}}-K_{11}^{\mathrm{mech}}\right), \\
& A_{1}^{*}(K)=-\frac{2 I}{\rho B^{3} \omega_{h}}\left(C_{21}^{\mathrm{eff}}-C_{21}^{\mathrm{mech}}\right), \\
& A_{2}^{*}(K)=-\frac{2 I}{\rho B^{4} \omega_{\alpha}}\left(C_{22}^{\mathrm{eff}}-C_{22}^{\mathrm{mech}}\right), \\
& A_{3}^{*}(K)=-\frac{2 I}{\rho B^{4} \omega_{\alpha}^{2}}\left(K_{22}^{\mathrm{eff}}-K_{22}^{\mathrm{mech}}\right), \\
& A_{4}^{*}(K)=-\frac{2 I}{\rho B^{3} \omega_{h}^{2}}\left(K_{21}^{\mathrm{eff}}-K_{21}^{\mathrm{mech}}\right),
\end{aligned}
$$

where $K=B \omega / U$ in the nondimensional reduced frequency, $U$ is the mean wind speed, $\omega_{\alpha}$ and $\omega_{h}$ are the circular frequencies with respect to the vertical and torsional motions, and $m$ and $I$ are the mass and mass moment of inertia of the bridge deck model per unit length. The flutter derivatives can be easily extracted once the system stiffness and the damping matrices are determined for both null wind speed and test wind speed experimental conditions. In general, the unknown parameters of a structural system can be identified by applying various system identification methods, according to the response output which is obtained through experimental means. However, due to the large size of the structure, as well as the complexity of creating an accurate mathematical model, and due to limitations of the measured output data, which might contain high level of noise, not all the system identification methods are applicable to many structural dynamics problems especially when their behavior might become highly nonlinear [25].

The displacement time history recorded from the experiment needs to be modified before applying any system identification method. According to the description of the ILS method, the first step is eliminating the noise interferences from the recorded response, to generate modified time displacement histories, which could be used in ILS method. A low-pass digital Butterworth filter was applied for both vertical and torsional responses time histories. In order to determine the cut-off frequencies for the Butterworth filter, Fast Fourier Transform was performed for the recorded data, to reveal the dominant frequencies for each wind speed case, as well as for the "no wind speed" conditions; from this analysis the upper and lower values for the cut-off frequency were selected. For the torsional motion, due to the property of the coupled flutter, the upper bound for the cut-off frequencies was slightly higher than the natural 


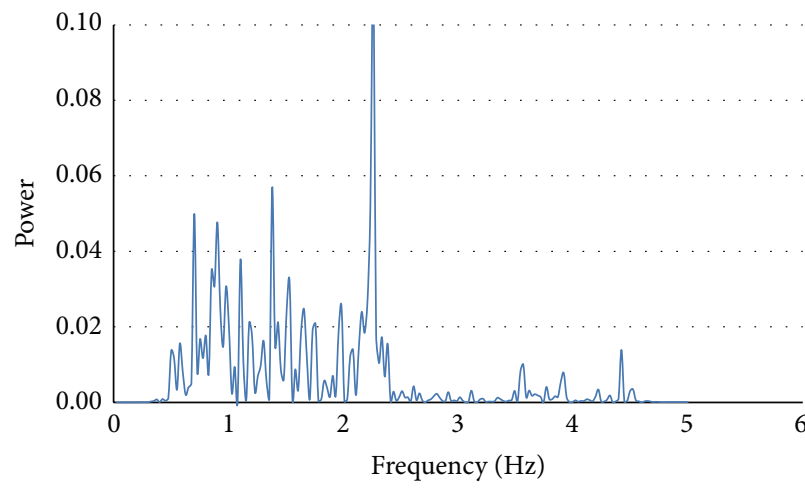

(a)

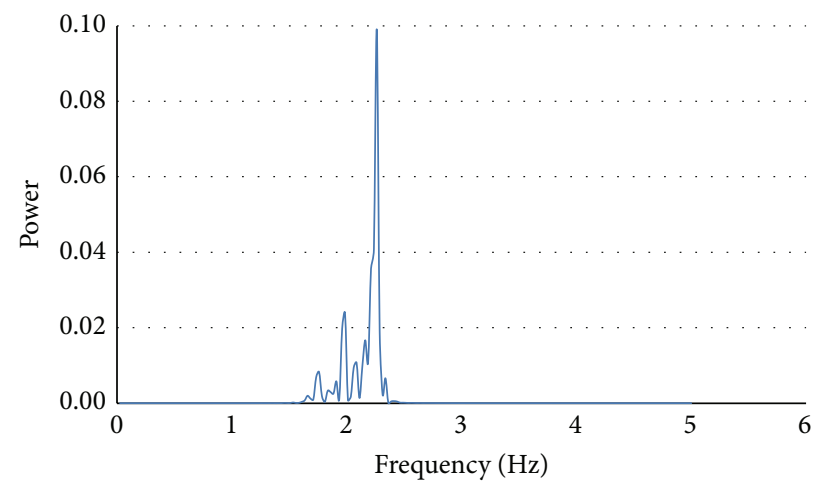

(b)

FIGURE 6: FFT analysis for (a) measured vertical response and (b) filtered vertical response.

frequency, at minimum wind speed of $3.0 \mathrm{~m} / \mathrm{s}$, and the lower bound is slightly lower than the minimum natural frequency at maximum wind speed of $13 \mathrm{~m} / \mathrm{s}$; on the contrary, for the vertical motion thus the principle for choosing the cut-off frequency was the reversed situation. It was found that the Butterworth low-pass filter can effectively remove the noisy high frequencies from the measured response. However, some changes in the magnitude of the frequency may be caused. As it can be noticed in Figure 6, the vertical frequency at the maximum wind speed of $13.00 \mathrm{~m} / \mathrm{s}$, where the nosiest data was recorded, decreased from $0.119 \mathrm{~Hz}$ to $0.10 \mathrm{~Hz}$ and the accuracy of the ILS identification method for the system parameters might be affected. On the other hand, the change in frequency values recorded for all the performed cases was within the tolerance limit of $10 \%$ to $15 \%$, thus no significant effect is expected. Once the time displacement histories were filtered, the finite difference formulation was applied to generate velocity and acceleration time histories for which a "windowing" operation was used to minimize the effect of the filter and of the finite difference method on the data by considering only the middle part of the three time histories for further calculations.

4.2. Flutter Derivatives for a Thin Plate and for the Multibox Bridge Deck Model. As shown by Simiu and Scanlan [1], an alternative to using the complicated ILS identification method, an approximate estimation of the flutter derivatives, can be made, according to Theodorsen thin plate theory. Theodorsen [26] first presented the theoretical formulation for modelling the flutter forces acting on a twodimensional airfoil (wing) section, in the incompressible potential flow; thus the theoretical expression for flutter derivatives expressed in terms of the Theodorsen function can be extracted by matching the aerodynamic force terms in Theodorsen expressions, with those from Scanlan formulas [22]. The flutter derivatives expressions obtained by this direct comparison are as follows:

$$
\begin{aligned}
& K H_{1}^{*}=-2 \pi F, \\
& K H_{2}^{*}=-\frac{\pi}{2}\left(1+F+\frac{4 G}{K}\right),
\end{aligned}
$$

$$
\begin{aligned}
K^{2} H_{3}^{*} & =-\pi\left(2 F-\frac{G K}{2}\right), \\
H_{4}^{*} & =\frac{\pi}{2}\left(1+\frac{4 G}{K}\right), \\
K A_{1}^{*} & =\frac{\pi F}{2}, \\
K A_{2}^{*} & =-\frac{\pi}{2}\left(\frac{1}{4}-\frac{G}{K}+\frac{F}{4}\right), \\
K^{2} A_{3}^{*} & =\frac{\pi}{2}\left(\frac{K^{2}}{32}+F-\frac{G K}{4}\right), \\
K^{2} A_{4}^{*} & =-\frac{\pi}{2}(K G),
\end{aligned}
$$

where $F(K)$ and $G(K)$ are the real and the imaginary parts of the Theodorsen functions $C(K)$, respectively. The comparisons between the theoretical expressions recommended by Theodorsen [26] and the experimental values showed a good agreement for an airfoil or a streamlined cross section [1]. For complex structures such as bridge deck models, the Theodorsen formulations could only indicate a similar trend for some of the flutter derivatives identified from experiments. The approximate formulations of $F(K)$ and $G(K)$ were adopted in this study as presented by Fung [27]:

$$
\begin{aligned}
& C(K)=F(K)+i G(K), \\
& F(K)=1-\frac{0.165}{1+(0.0455 / K)^{2}}-\frac{0.335}{1+(0.3 / K)^{2}}, \\
& G(K)=-\frac{(0.165 \times 0.0455) / K}{1+(0.0445 / K)^{2}}-\frac{(0.335 \times 0.3) / K}{1+(0.3 / K)^{2}},
\end{aligned}
$$

where $K=B \omega / U$ is the reduced frequency, $B$ is the width of the thin plate, and $\omega$ is the natural frequency of the motion.

As it can be noticed from Figure 7(a), almost all the flutter derivatives extracted at $0^{\circ}$ angle of attack from the experiments by employing ILS method, for the multideck bridge section, registered similar trends with Theodorsen's theoretical estimation for the thin plate, except for 

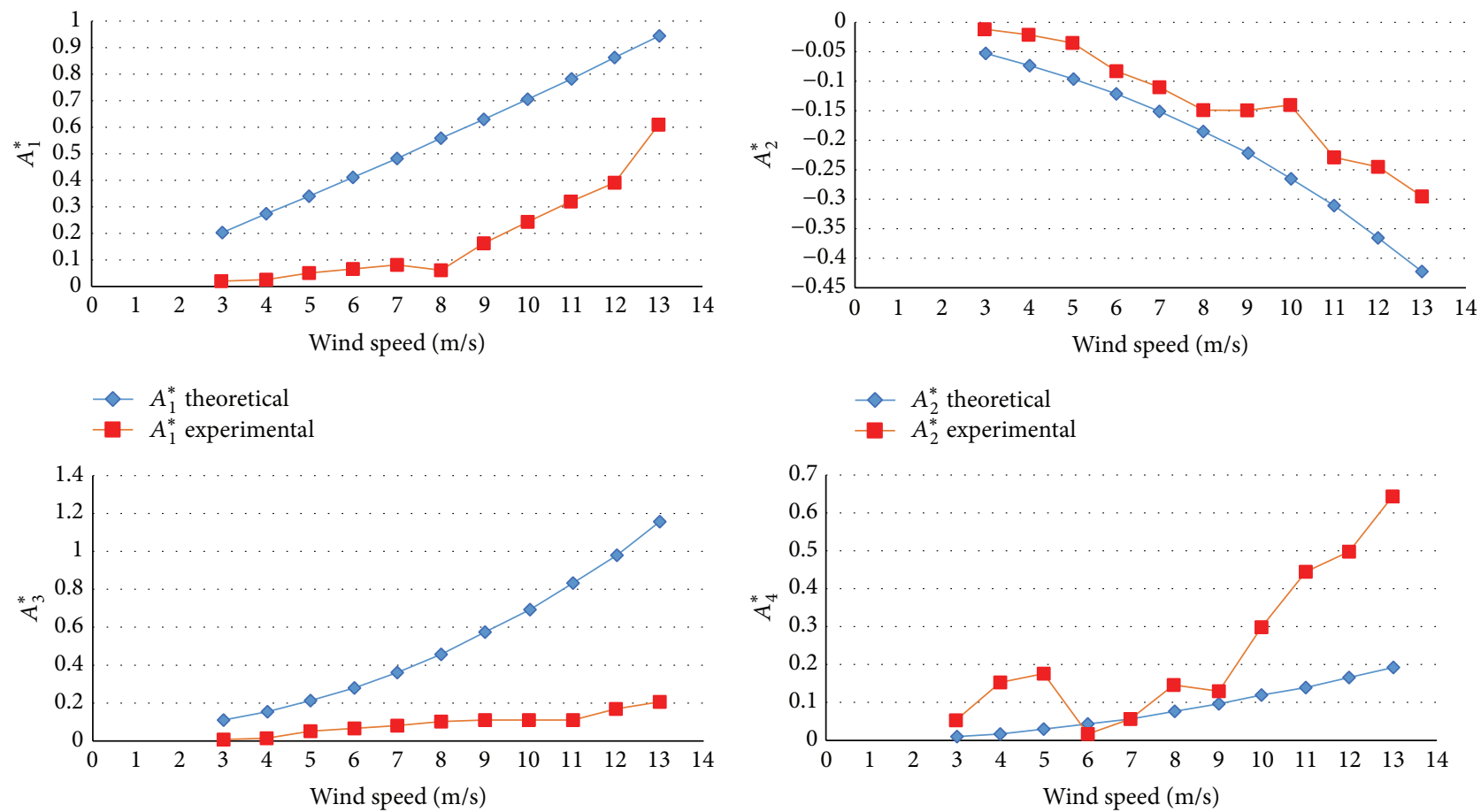

$\checkmark A_{3}^{*}$ theoretical

$A_{3}^{*}$ experimental

$$
\begin{aligned}
& \checkmark A_{4}^{*} \text { theoretical } \\
& -A_{4}^{*} \text { experimental }
\end{aligned}
$$

(a)
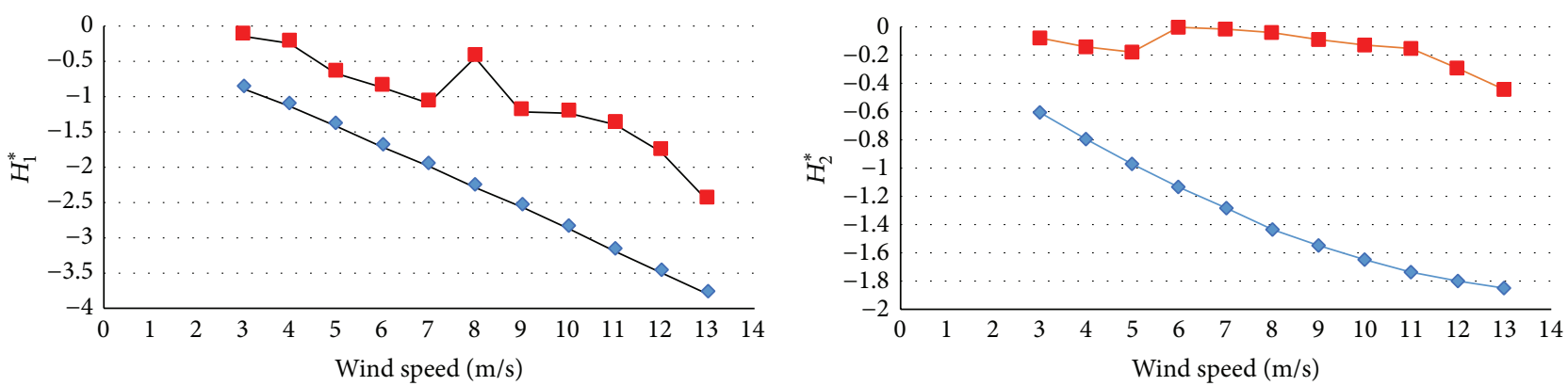

$\checkmark-H_{1}^{*}$ theoretical

$H_{1}^{*}$ experimental
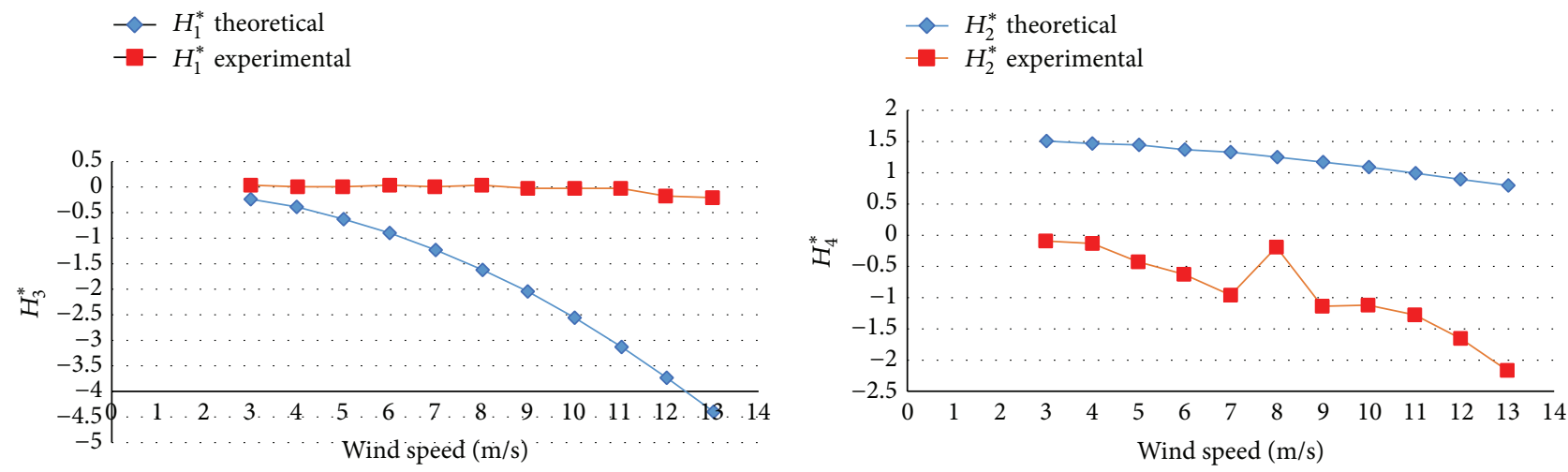

$H_{3}^{*}$ theoretical

$H_{3}^{*}$ experimental

$\checkmark H_{4}^{*}$ theoretical

$H_{4}^{*}$ experimental

(b)

Figure 7: (a) Flutter derivatives $A_{1}^{*}, A_{2}^{*}, A_{3}^{*}$, and $A_{4}^{*}$ for the multibox bridge deck estimated by the Theodorsen thin plate theory and determined from experiments. (b) Flutter derivatives $H_{1}^{*}, H_{2}^{*}, H_{3}^{*}$, and $H_{4}^{*}$ for the multibox bridge deck estimated by the Theodorsen thin plate theory and determined from experiments. 


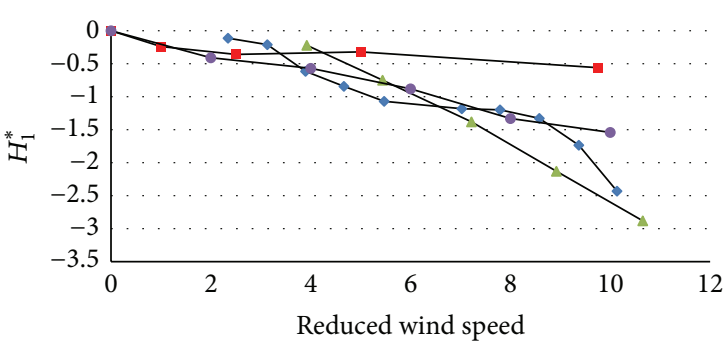

(a)

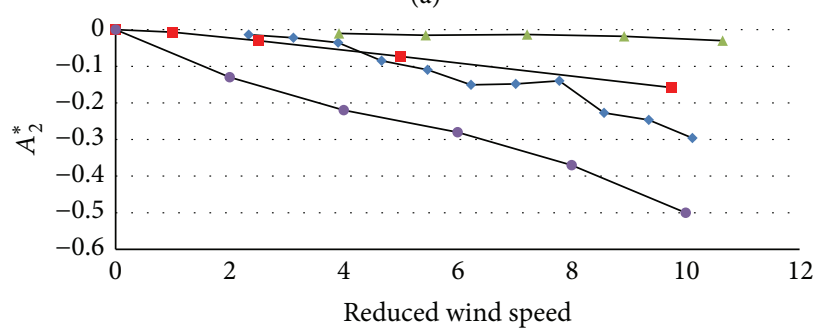

(b)

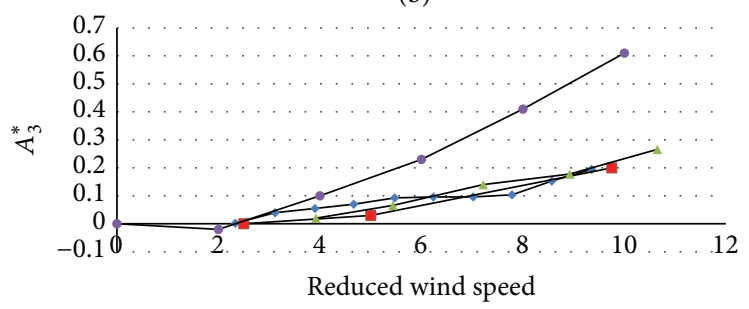

$\multimap$ Multibox bridge (four decks)
- Messina Bridge (three decks)
$\rightarrow-$ Höga Kusten Bridge (one deck)
$\rightarrow-$ Stonecutters Bridge (twin-deck)

(c)

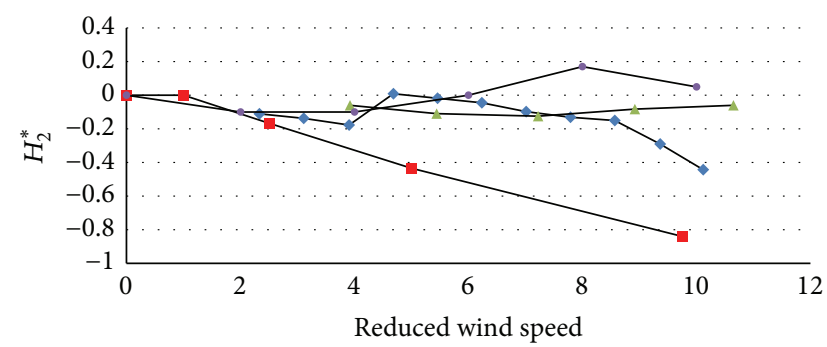

(d)

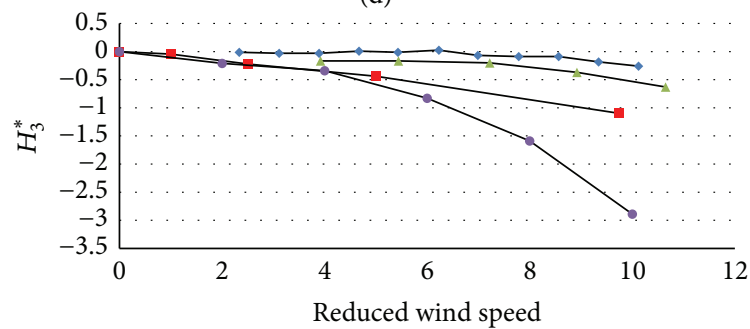

(e)

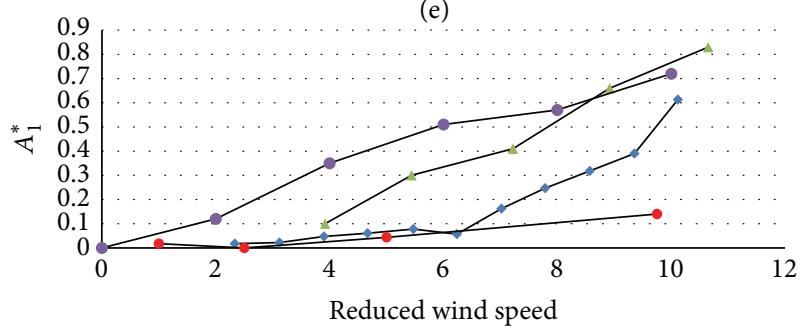

$\rightarrow$ Multibox bridge (four decks)
$\rightarrow$ Messina Bridge (three decks)
$\rightarrow-$ Höga Kusten Bridge (one deck)
$\rightarrow-$ Stonecutters Bridge (twin-deck)

(f)

FIgURE 8: Direct and cross-flutter derivatives comparison for Höga Kusten Bridge, one box deck [28], Stonecutters Bridge, a twin-box deck [13], Messina Bridge three-box deck [29], and multibox bridge deck (current experiment).

the flutter derivative $A_{4}^{*}$, for which the experiment showed larger variation. Also, except for $A_{2}^{*}$ and $A_{4}^{*}$, the magnitudes of the other flutter derivatives based on Theodorsen's theoretical functions were all higher than those obtained from the multibox deck experiments, especially for the high wind speeds range. In general the flutter derivatives should be close to null value at the low wind speeds; however, for the case of $H_{4}^{*}$ the theoretical value started from 1.5 (Figure 7(b)) decreasing along with the wind speed. This shows that Theodorsen's theory for thin plate is not applicable for identifying flutter derivative of $H_{4}^{*}$ for a multibox bridge deck section. Despite these discrepancies, the similarity in aerodynamic properties between the streamlined multibox deck and a thin plate section can be confirmed by the general trends of the theoretical and experimental flutter derivatives, which are in good agreement.

\subsection{Flutter Derivatives Comparison for Different Types of} Bridge Decks. In order to evaluate the aerodynamic properties of the multibox bridge deck model proposed herewith, the flutter derivatives identified from the experiments were compared with the flutter derivatives reported for other bridge decks of similar configuration. According to the original work of Scanlan and Tomoko, [22], which confirmed that that the errors that occur for the flutter derivatives $H_{4}^{*}$ and $A_{4}^{*}$ do not affect significantly the overall flutter behavior of the bridge, only six flutter derivatives were considered for the current comparison. The reduced wind speed was used for reporting the flutter derivatives extracted from different wind tunnel tests, for various types of bridge decks, which is defined as [22]

$$
U_{\text {red }}=\frac{U}{(B \cdot f)},
$$

where $U$ is the mean wind speed, $B$ is the width of the bridge deck, and $f$ is the natural frequency of the bridge deck. Comparison with the flutter derivatives reported for $0^{\circ}$ angle of attack for Höga Kusten Bridge, which has a single box deck [28], for Stonecutters Bridge, with a twin-box deck [13], and for Messina Bridge, which has a three-box deck [29], is collected and the results are presented below.

$H_{1}^{*}$ is one of the three direct flutter derivatives which relates to the aerodynamic damping, in the vertical vibration mode, and from Figure 8(a) it was noticed that, for all the bridge deck sections reported, $H_{1}^{*}$ values were negative, thus indicating a positive aerodynamic damping. The negative 
values were also observed for the multibox deck section, starting from -0.088 and up to -2.42 (Figure $8(\mathrm{a})$ ), which is close to flutter derivative reported for the Stonecutters Bridge twin-deck section. $A_{2}^{*}$ flutter derivative represents the dimensionless aerodynamic damping term for torsional vibration; thus the negative values registered for $A_{2}^{*}$ implies positive aerodynamic damping acting for the torsional vibration. From Figure 8(b), it can be noticed that, for the wind attack angle of $0^{\circ}$, the comparison of $A_{2}^{*}$ for the current multibox deck and for the Messina Bridge three-box bridge decks was very similar. The comparison showed that $A_{3}^{*}$ flutter derivative of the currently investigated multibox bridge deck, was very similar with $A_{3}^{*}$ flutter derivatives of the Messina Bridge (three-box deck section) and of the Höga Kusten Bridge (one box deck section), as it can be noticed in Figure 8(c).

The direct flutter derivatives can be obtained through the 1-DOF vibration; however the identification of the crossflutter terms requires coupled motion vibration. Therefore, the cross-flutter derivatives obtained from the experiments through the ILS system identification displayed more discrepancies than the direct flutter derivatives. The comparison of the dimensionless $\mathrm{H}_{2}^{*}$ flutter derivative for the multibox bridge deck, which relates to the torsional damping in the coupled motion, is shown in Figure 8(c). The trend approaches the values reported for Messina Bridge deck; then it deviates towards the curve of $\mathrm{H}_{2}^{*}$ flutter derivative reported for the Höga Kusten Bridge deck, for higher reduced wind speed; finally $H_{2}^{*}$ flutter derivative reaches values between the flutter derivatives of Stonecutters and the Messina Bridge decks. It is interesting to notice that, for the current multibox bridge deck, the other dimensionless crossflutter derivative term $\mathrm{H}_{3}^{*}$, corresponding to the lift force contribution from the torsional displacement, presents the smallest values among other three bridge deck types for the entire reduced wind speeds range investigated (Figure $8(d)$ ). The comparison of the third dimensionless cross-flutter derivative $A_{1}^{*}$ is shown in Figure $8(\mathrm{e})$. The curve of $A_{1}^{*}$ derivative for multibox deck is very similar to the results reported for Messina Bridge deck section until a reduced wind speed of around 6.0 and then gradually increases, locating between the Stonecutters and Messina Bridge decks. Overall, except for $H_{3}^{*}$ flutter derivative, which was very small, $H_{1}^{*}, H_{2}^{*}, A_{1}^{*}, A_{2}^{*}$, and $A_{3}^{*}$ flutter derivatives registered values between the results reported for Messina Bridge triplebox deck and the Stonecutters Bridge twin-deck, indicating a very good aerodynamic performance for this new type of multibox bridge deck.

Figures 9(a) and 9(b) present the flutter derivatives for the angles of attack $-4^{\circ}$ to $4^{\circ}$, identified from the experiments performed on the multibox bridge deck model. The response measured for higher angles of attack contained too much noisy data, which could not be filtered out entirely; therefore the flutter derivatives could not be calculated. Among the eight flutter derivatives, $H_{2}^{*}, H_{4}^{*}$, and $A_{4}^{*}$ showed more variation along the general increment or decrement trends. For angles of attack $-4^{\circ}$ to $4^{\circ}, H_{1}^{*}, H_{2}^{*}$, and $H_{3}^{*}$ decreased with the reduced wind speed, especially for the $2^{\circ}$ case, where a sudden drop was noticed for reduced wind speeds higher than $8 . H_{4}^{*}$ had an overall increasing trend, except for the $2^{\circ}$ case where a gradual decrease was registered, after a sharp increase at 5.3 reduced wind speed; this discrepancy might be caused by the noise recorded in the measurement data. $A_{1}^{*}$ and $A_{3}^{*}$ increased with the reduced wind speed for all the angles of attack reported, while $A_{2}^{*}$ had an overall decreasing tendency; however small variations were noticed in the evolution of $A_{4}^{*}$ flutter derivative, but overall the values were still increasing for the angles of attack $-4^{\circ},-2^{\circ}$, and $4^{\circ}$. For $2^{\circ}$ case however a gradual decrease was registered, which again might be caused by the errors in the measured experimental data.

4.4. Critical Flutter Velocity for the Multibox Bridge Deck. In general the bridge decks start vibrating at high wind speeds when the input energy from the wind flow gradually becomes larger than the energy dissipated through the bridge mechanical damping system. When the effective damping, represented by the difference between the mechanical and aerodynamic damping, becomes null, the oscillating motion of the deck starts diverging and this phenomenon is called the critical flutter condition, while the wind speed where this occurs is called the critical flutter velocity Simiu and Scanlan [1]. Selberg [30] introduced a simplified empirical expression for estimating the critical flutter speed. However, this equation is based on the thin plate theory and is not representing the critical flutter speed of bridge deck sections. Therefore an alternative method for estimating the critical flutter speed of the current multibox bridge deck was employed; namely, a Fast Fourier Analysis was performed for the vertical and torsional responses recorded during the experiments and it was noticed that, at around $13.0 \mathrm{~m} / \mathrm{s}$ (reduced wind speed 10.13), the vertical frequency value was identical with the torsional frequency, at $2.26 \mathrm{~Hz}$, for the case of $0^{\circ}$ angle of attack. Thus, the critical coupled flutter wind speed for the prototype could be calculated based on the reduced wind speed similarity recommended by Scanlan and Tomoko [22]:

$$
\left(\frac{U_{\mathrm{cr}}}{B f}\right)_{m}=\left(\frac{U_{\mathrm{cr}}}{B f}\right)_{p},
$$

where the index $m$ represents the model tested in the wind tunnel and the index $p$ represents the prototype of the multibox bridge deck. However, since the frequency of the prototype has not been finalized yet, several frequencies between $0.1 \mathrm{~Hz}$ and $0.5 \mathrm{~Hz}$ were considered when estimating the critical flutter velocity. The multibox bridge deck with no further modifications, such as stabilizer, wind shields, or barriers, can sustain a critical wind speed of $62.8 \mathrm{~m} / \mathrm{s}$, for a frequency of $0.1 \mathrm{~Hz}$, which is slightly higher than the design wind speed of $60.0 \mathrm{~m} / \mathrm{s}$ reported for the Messina Bridge deck [31]. However, when the natural frequency of the prototype reaches $0.2 \mathrm{~Hz}$, the critical flutter wind speed is $125.6 \mathrm{~m} / \mathrm{s}$, which is much larger than the Great Belt flutter wind speed, estimated at $74.0 \mathrm{~m} / \mathrm{s}$ [32]. Also the critical flutter speed of twin-box decks, would vary; for example, for the Xihoumen Bridge a critical flutter speed of $U_{\mathrm{cr}}=89.3 \mathrm{~m} / \mathrm{s}$ was estimated [11], and for the Yi Sun-Sin Bridge a very high flutter critical velocity of $U_{\mathrm{cr}}=120.0 \mathrm{~m} / \mathrm{s}$ was reported [33]. 

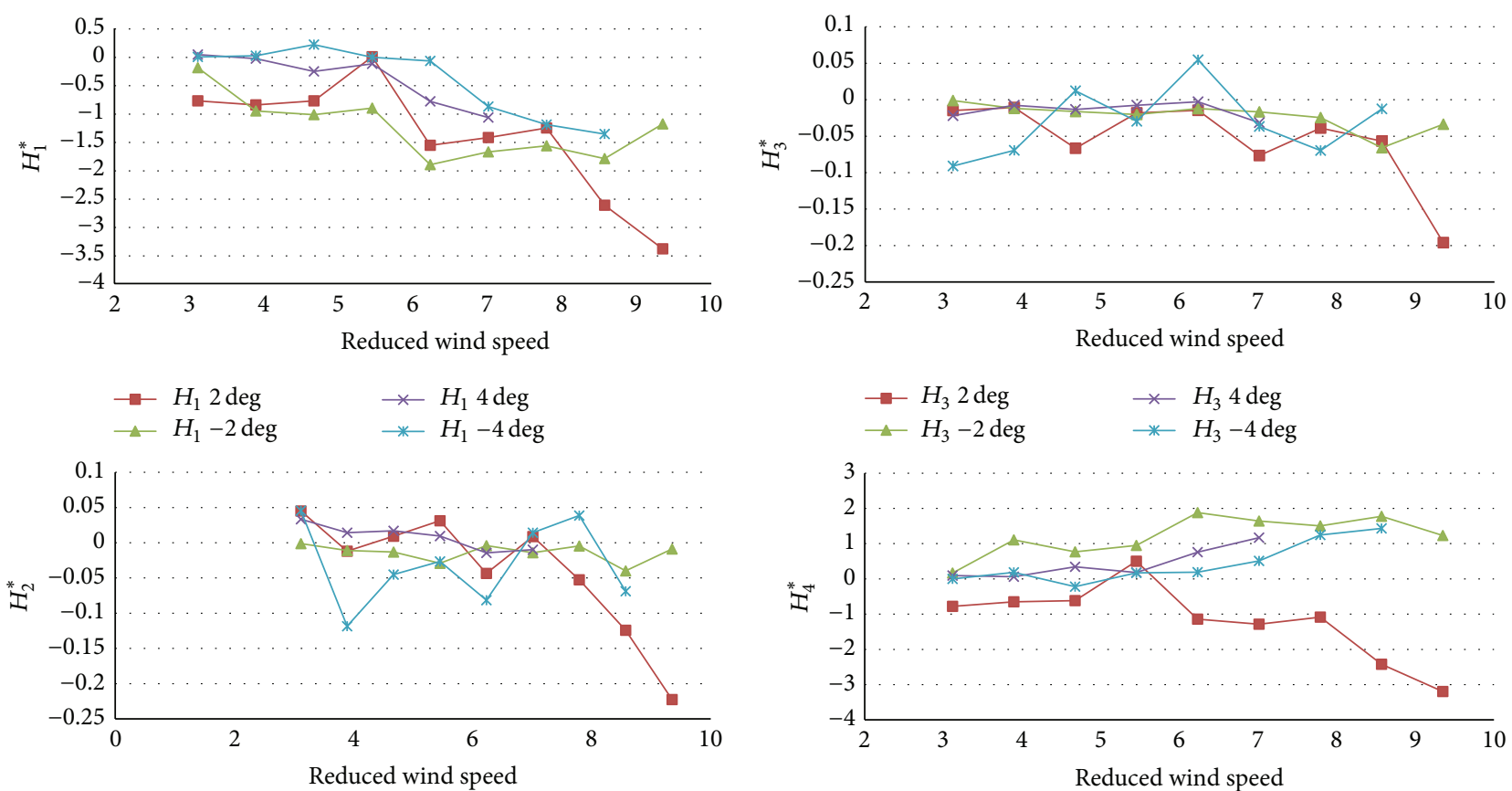

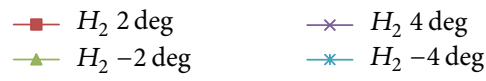

$$
\rightarrow H_{4} 2 \mathrm{deg} \quad \rightarrow H_{4} 4 \mathrm{deg}
$$

(a)
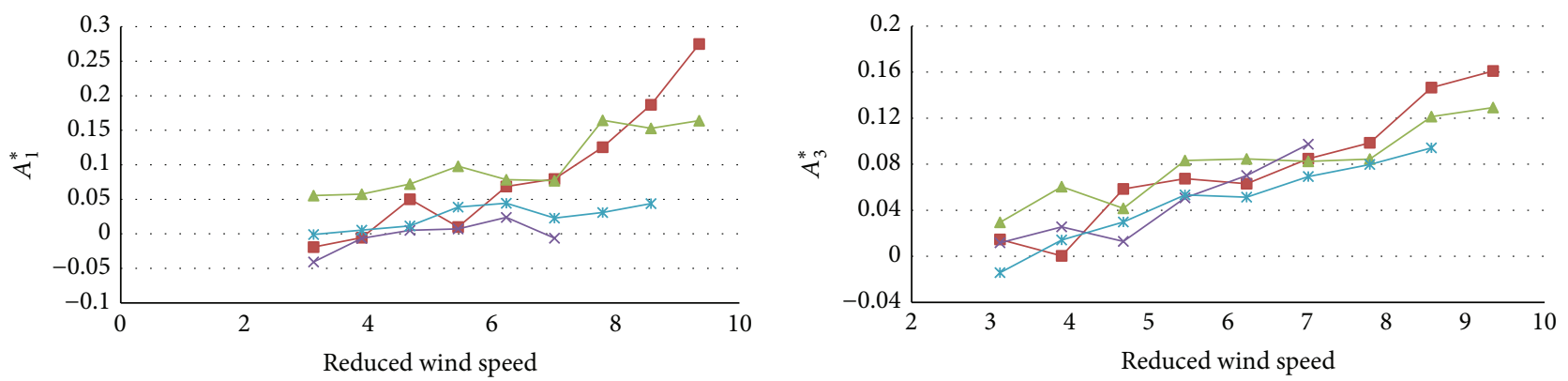

$$
\begin{array}{ll}
\rightarrow A_{1} 2 \mathrm{deg} & * A_{1} 4 \mathrm{deg} \\
\rightarrow A_{1}-2 \mathrm{deg} & \rightarrow A_{1}-4 \mathrm{deg}
\end{array}
$$
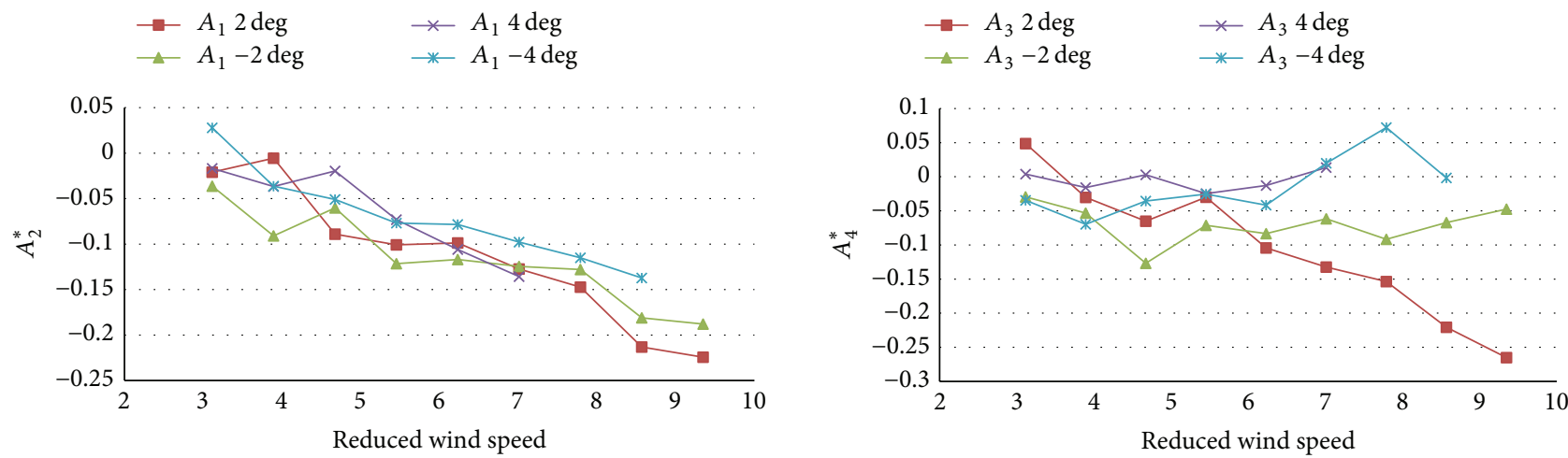

$$
\begin{array}{ll}
\rightarrow A_{2} 2 \mathrm{deg} & \rightarrow A_{2} 4 \mathrm{deg} \\
-A_{2}-2 \mathrm{deg} & * A_{2}-4 \mathrm{deg}
\end{array}
$$$$
\begin{array}{ll}
\rightarrow A_{4} 2 \mathrm{deg} & * A_{4} 4 \mathrm{deg} \\
\rightarrow-A_{4}-2 \mathrm{deg} & * A_{4}-4 \mathrm{deg}
\end{array}
$$

(b)

Figure 9: (a) Flutter derivatives $H_{1}^{*}, H_{2}^{*}, H_{3}^{*}$, and $H_{4}^{*}$ for the multibox bridge deck for angles of attack of $-4^{\circ},-2^{\circ}, 2^{\circ}$, and $4^{\circ}$. (b) Flutter derivatives $A_{1}^{*}, A_{2}^{*}, A_{3}^{*}$, and $A_{4}^{*}$ for the multibox bridge deck for angles of attack of $-4^{\circ},-2^{\circ}, 2^{\circ}$, and $4^{\circ}$. 
Moreover, if the natural frequency of the first vertical mode of the currently proposed multibox prototype bridge would vary to $0.3 \mathrm{~Hz}$ or higher, the critical flutter speed would be $188.4 \mathrm{~m} / \mathrm{s}$ or higher. Thus experimental investigation of the new multibox bridge deck configuration showed that the flutter aerodynamic instability will be encountered for wind speeds much higher than those reported for other twin or triple-box bridge decks.

\section{Conclusions}

A new optimized type of deck consisting of four connected airfoil bridge decks was experimentally investigated and eight flutter derivatives were identified from the free vibration time displacement histories. The ILS identification method for flutter derivatives was selected among various methods, due to the convenience in identifying the system parameters. The comparison with the flutter derivatives estimated by Theodorsen thin plate theory confirms that the aerodynamic behavior of the multibox bridge deck section is similar to that of the streamlined sections, despite the discrepancies in the maximum and minimum values. Flutter derivatives reported for Messina, Stonecutters, and Höga Kusten Bridge decks were consulted as reference values and were compared with those obtained for the currently investigated multibox bridge deck model. As expected, the direct flutter terms showed close resemblances with the values of the Messina Bridge, except for $H_{1}^{*}$ flutter derivative which was closer to the Stonecutters Bridge deck. On the other hand, for the crossflutter derivatives, the values recorded for the multibox deck were different than the reference values, which indicates the unique aerodynamic properties of the multibox deck section. For a natural frequency of the multibox bridge deck prototype of $0.2 \mathrm{~Hz}$, the critical flutter wind speed of $125.6 \mathrm{~m} / \mathrm{s}$ was estimated.

\section{Competing Interests}

The authors declare that there are no competing interests regarding the publication of this paper.

\section{Acknowledgments}

The current research project was supported by the Natural Sciences and Engineering Research Council of Canada (NSERC). The authors would like to acknowledge the support of Dr. John Hayes and Mr. Alex Proctor during the experiments.

\section{References}

[1] E. Simiu and R. H. Scanlan, Wind Effects on Structures: Fundamentals and Applications to Design, John Wiley \& Sons, Ontario, Canada, 3rd edition, 1996.

[2] E. Simiu and T. Miyata, Design of Buildings and Bridges for Wind: A Practical Guide for ASCE-7 Standard Users and Designers of Special Structures, John Wiley \& Sons, New York, NY, USA, 2006.
[3] L. Caracoglia and N. P. Jones, "Time domain vs. frequency domain characterization of aeroelastic forces for bridge deck sections," Journal of Wind Engineering and Industrial Aerodynamics, vol. 91, no. 3, pp. 371-402, 2003.

[4] A. Larsen, "Aerodynamic aspects of the final design of the 1,624 $\mathrm{m}$ suspension bridge across the Great Belt," Journal of Wind Engineering and Industrial Aerodynamics, vol. 48, no. 2-3, pp. 261-285, 1993.

[5] M. Matsumoto, K. Mizuno, K. Okubo, Y. Ito, and H. Matsumiya, "Flutter instability and recent development in stabilization of structures," Journal of Wind Engineering and Industrial Aerodynamics, vol. 95, no. 9-11, pp. 888-907, 2007.

[6] J. Xie, H. Tanaka, R. L. Wardlaw, and M. G. Savage, "Buffeting analysis of long span bridges to turbulent wind with yaw angle," Journal of Wind Engineering and Industrial Aerodynamics, vol. 37, no. 1, pp. 65-77, 1991.

[7] G. Diana, M. Falco, S. Bruni et al., "Comparisons between wind tunnel tests on a full aeroelastic model of the proposed bridge over Stretto di Messina and numerical results," Journal of Wind Engineering and Industrial Aerodynamics, vol. 54-55, pp. 101-113, 1995.

[8] K. C. S. Kwok, X. R. Qin, C. H. Fok, and P. A. Hitchcock, "Wind-induced pressures around a sectional twin-deck bridge model: effects of gap-width on the aerodynamic forces and vortex shedding mechanisms," Journal of Wind Engineering and Industrial Aerodynamics, vol. 110, pp. 50-61, 2012.

[9] S. Lee, S.-D. Kwon, and J. Yoon, "Reynolds number sensitivity to aerodynamic forces of twin box bridge girder," Journal of Wind Engineering and Industrial Aerodynamics, vol. 127, pp. 59-68, 2014.

[10] G. Diana, F. Resta, and D. Rocchi, "A new numerical approach to reproduce bridge aerodynamic non-linearities in time domain," Journal of Wind Engineering and Industrial Aerodynamics, vol. 96, no. 10-11, pp. 1871-1884, 2008.

[11] Y. J. Ge and H. F. Xiang, "Recent development of bridge aerodynamics in China," Journal of Wind Engineering and Industrial Aerodynamics, vol. 96, no. 6-7, pp. 736-768, 2008.

[12] T. Miyata, "Significance of aero-elastic relationship in windresistant design of long-span bridges," Journal of Wind Engineering and Industrial Aerodynamics, vol. 90, no. 12-15, pp. 14791492, 2002.

[13] M. C. H. Hui, "Full-bridge aero-elastic model wind tunnel tests for the Stonecutters Bridge," HKIE Transactions, vol. 20, no. 2, pp. 109-123, 2013.

[14] Y. L. Xu, J. M. Ko, and Z. Yu, "Modal analysis of towercable system of Tsing Ma long suspension bridge," Engineering Structures, vol. 19, no. 10, pp. 857-867, 1997.

[15] G. L. Larose, A. Damsgaard, G. Diana, and M. Falco, "Wind tunnel investigations of the power for the Stretto di Messina Bridge," Journal of Wind Engineering and Industrial Aerodynamics, vol. 48, no. 2-3, pp. 379-393, 1993.

[16] T. Y. Lin and P. Chow, "Gibraltar strait crossing-a challenge to bridge and structural engineers," Structural Engineering International, vol. 1, no. 2, pp. 53-58, 1991.

[17] W. Wangsadinata, P. Chow, and T. Y. Lin, "A prospective bridge crossing using ultra-long bridge spans between Java and Sumatera," in Proceedings of the Seminar on Underground, Urban and Commuter Transportation Technology, BPPT-JICA, Jakarta, Indonesia, September 1992.

[18] G. Bartoli, P. D’Asdia, S. Febo, C. Mannini, S. Noè, and L. Procino, "Innovative configurations for long-span suspension 
bridges," in Proceedings of the 5th European and African Conference on Wind Engineering (EACWE '09), Florence, Italy, July 2009.

[19] A. G. Chowdhury and P. P. Sarkar, "A new technique for identification of eighteen flutter derivatives using a threedegree-of-freedom section model," Engineering Structures, vol. 25, no. 14, pp. 1763-1772, 2003.

[20] G. Diana, G. Fiammenghi, M. Belloli, and D. Rocchi, "Wind tunnel tests and numerical approach for long span bridges: the Messina bridge," Journal of Wind Engineering and Industrial Aerodynamics, vol. 122, pp. 38-49, 2013.

[21] G. Diana, F. Resta, A. Zasso, M. Belloli, and D. Rocchi, "Forced motion and free motion aeroelastic tests on a new concept dynamometric section model of the Messina suspension bridge," Journal of Wind Engineering and Industrial Aerodynamics, vol. 92, no. 6, pp. 441-462, 2004.

[22] R. H. Scanlan and J. J. Tomko, "Airfoil and bridge deck flutter derivatives," ASCE Journal of the Engineering Mechanics, vol. 97, no. 6, pp. 1717-1737, 1971.

[23] P. P. Sarkar, N. P. Jones, and R. H. Scanlan, "Identification of aeroelastic parameters of flexible bridges," Journal of Engineering Mechanics, vol. 120, no. 8, pp. 1718-1742, 1994.

[24] M. Gu and X. R. Qin, "Direct identification of flutter derivatives and aerodynamic admittances of bridge decks," Journal of Wind Engineering and Industrial Aerodynamics, vol. 26, no. 14, pp. 2161-2172, 2004.

[25] H. Imai, C.-B. Yun, O. Maruyama, and M. Shinozuka, "Fundamentals of system identification in structural dynamics," Probabilistic Engineering Mechanics, vol. 4, no. 4, pp. 162-173, 1989.

[26] T. Theodorsen, "General theory of aerodynamic instability and the mechanism of flutter," Tech. Rep. 496, National Advisory Committee for Aeronautics (NACA), Washington, DC, USA, 1935.

[27] Y. C. Fung, An Introduction to the Theory of Aeroelasticity, Dove Publications, 2002.

[28] X. Xu, "Parametric studies on relationships between flutter derivatives of slender bridge," Applied Mathematics and Mechanics, vol. 30, no. 2, pp. 237-245, 2009.

[29] A. Baldomir, I. Kusano, S. Hernandez, and J. A. Jurado, "A reliability study for the Messina Bridge with respect to flutter phenomena considering uncertainties in experimental and numerical data," Computers and Structures, vol. 128, pp. 91-100, 2013.

[30] A. Selberg, Oscillation and Aerodynamic Stability of Suspension Bridge, vol. 13 of Acta Polytechnica Scandinavica, Norges Teknisk-Naturvitenskapelige Forskningsrad, 1961.

[31] F. Brancaleoni and G. Diana, "The aerodynamic design of the Messina Straits Bridge," Journal of Wind Engineering and Industrial Aerodynamics, vol. 48, no. 2-3, pp. 395-409, 1993.

[32] H. Zhan and T. Fang, "Flutter stability studies of Great Belt East Bridge and Tacoma Narrows Bridge by CFD numerical simulation," in Proceedings of the7th International Colloquium on Bluff Body Aerodynamics and Applications (BBAA7), Shanghai, China, 2012.

[33] H. B. Gil, "Bridges in Korea long span bridges," in Proceedings of the Seminar at the Norwegian Public Roads Administration, 2012. 


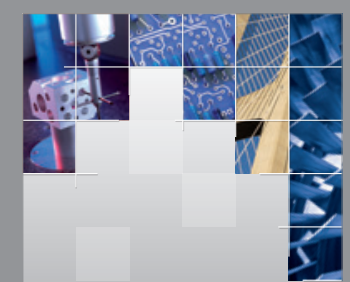

\section{Enfincering}
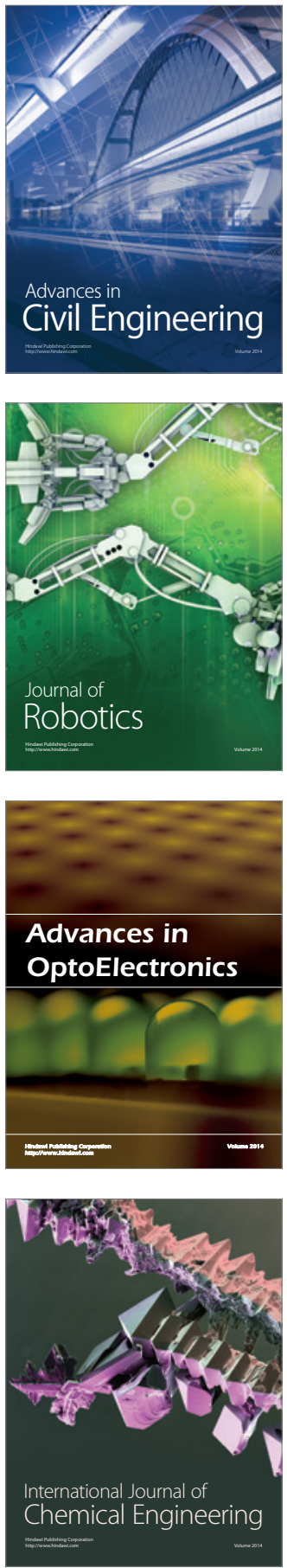

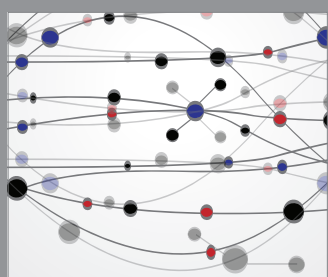

The Scientific World Journal

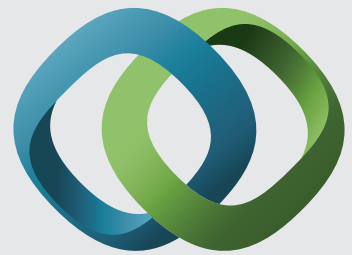

\section{Hindawi}

Submit your manuscripts at

http://www.hindawi.com
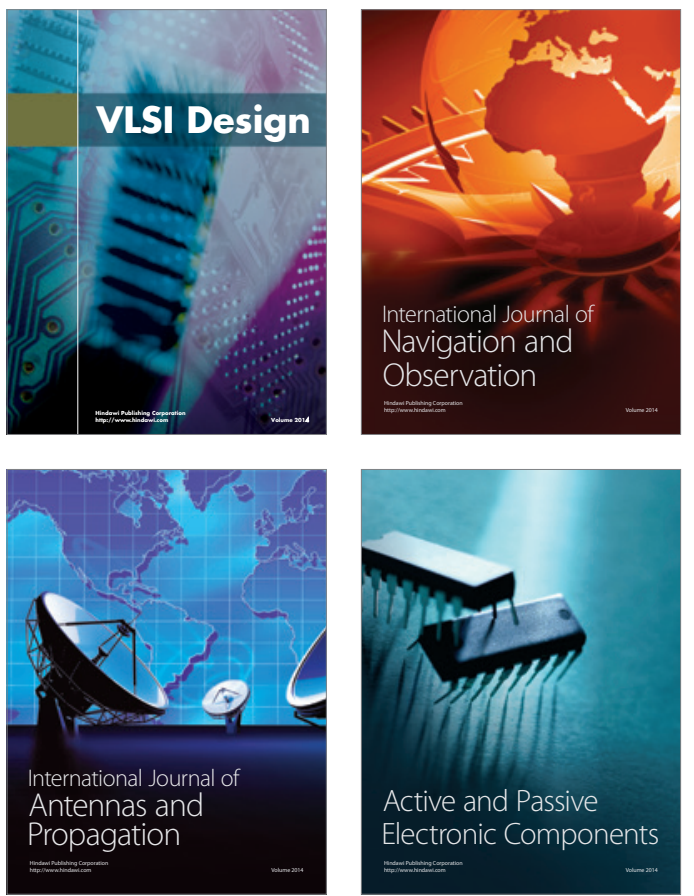
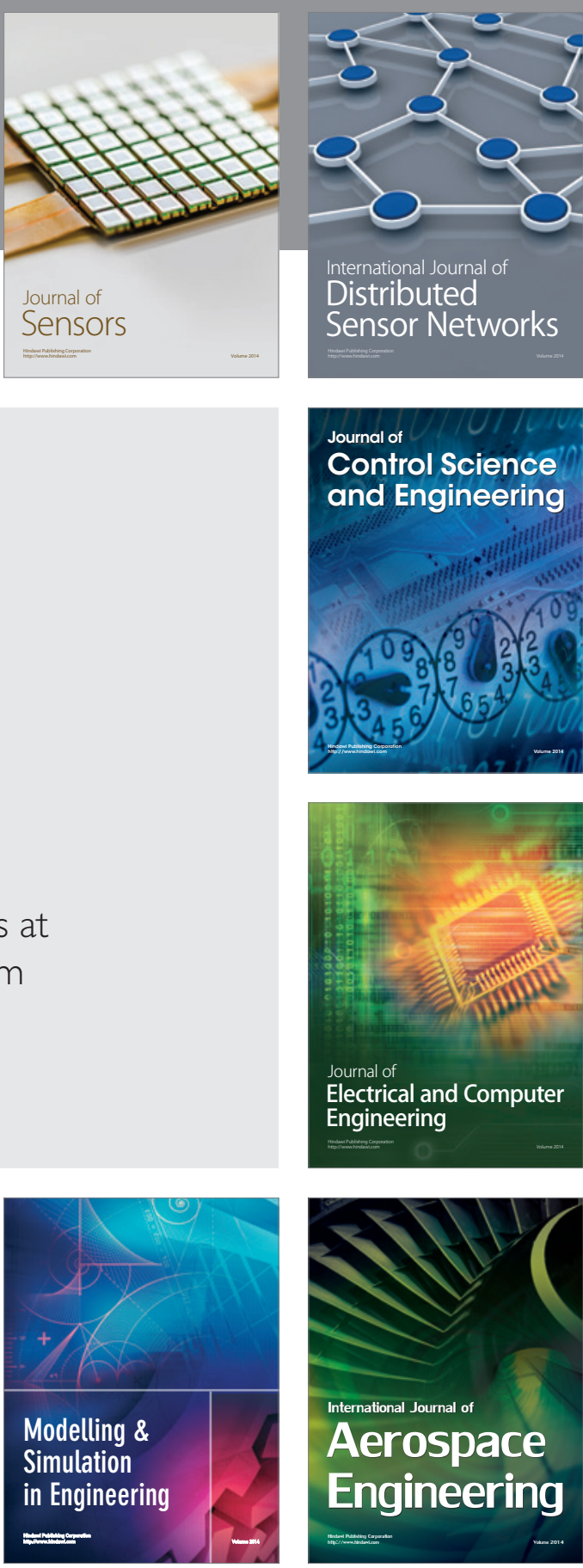

International Journal of

Distributed

Sensor Networks

Journal of

Control Science

and Engineering
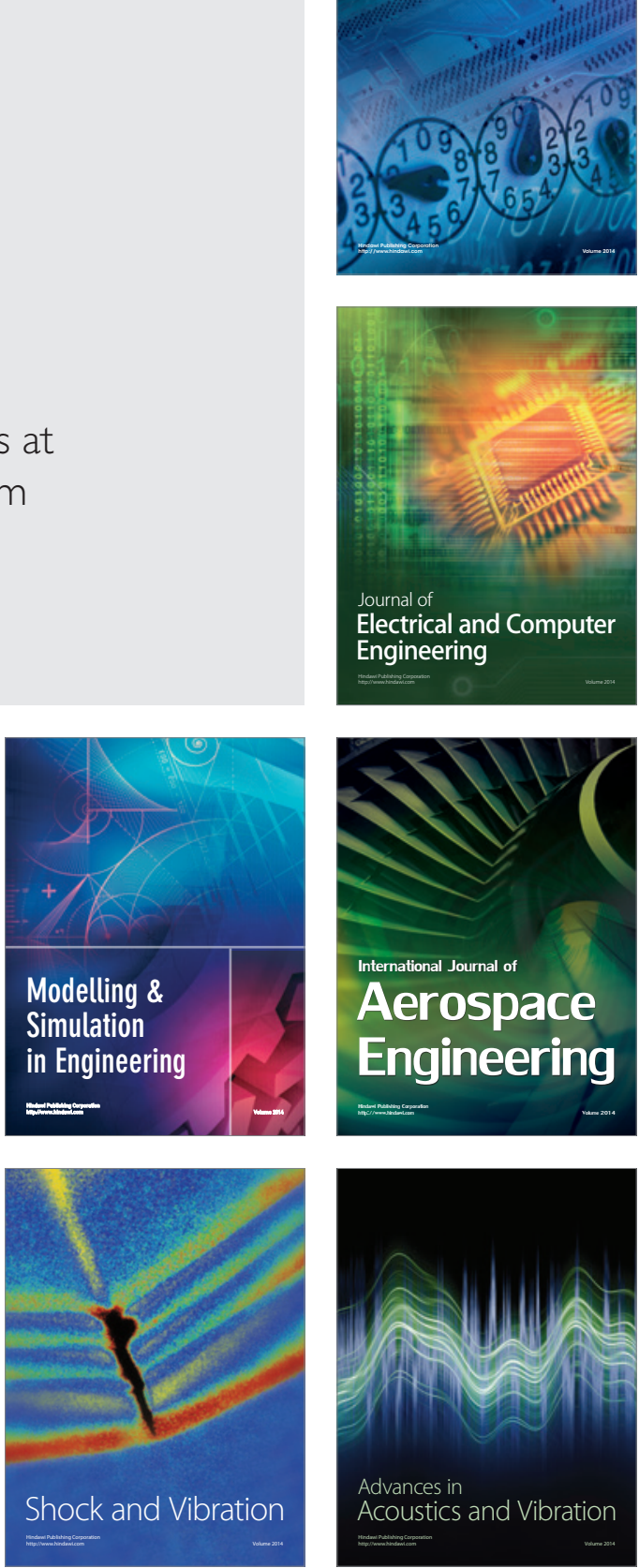